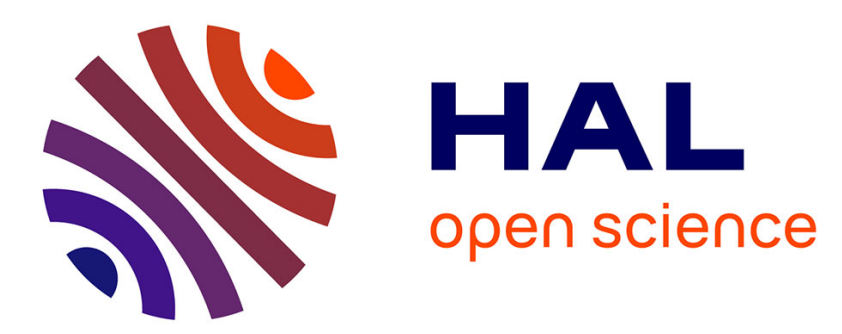

\title{
Transcriptome analysis identifies genes involved in sex determination and development of Xenopus laevis gonads
}

\author{
Rafal P. Piprek, M. Damulewicz, M. Kloc, J.Z. Kubiak
}

\section{To cite this version:}

Rafal P. Piprek, M. Damulewicz, M. Kloc, J.Z. Kubiak. Transcriptome analysis identifies genes involved in sex determination and development of Xenopus laevis gonads. Differentiation, 2018, 100, pp.46-56. 10.1016/j.diff.2018.02.004 . hal-01739955

HAL Id: hal-01739955

https://hal-univ-rennes1.archives-ouvertes.fr/hal-01739955

Submitted on 27 Apr 2018

HAL is a multi-disciplinary open access archive for the deposit and dissemination of scientific research documents, whether they are published or not. The documents may come from teaching and research institutions in France or abroad, or from public or private research centers.
L'archive ouverte pluridisciplinaire HAL, est destinée au dépôt et à la diffusion de documents scientifiques de niveau recherche, publiés ou non, émanant des établissements d'enseignement et de recherche français ou étrangers, des laboratoires publics ou privés. 


\section{Transcriptome analysis identifies genes involved in sex determination and development of Xenopus laevis gonads}

Rafal P. Piprek $^{1^{*}}$, Milena Damulewicz ${ }^{2}$, Malgorzata Kloc ${ }^{3,4,5}$, Jacek Z. Kubiak ${ }^{6,7}$

${ }^{1}$ Department of Comparative Anatomy, Institute of Zoology and Biomedical Research, Jagiellonian University, Krakow, Poland

${ }^{2}$ Department of Cell Biology and Imagining, Institute of Zoology and Biomedical Research, Jagiellonian University, Krakow, Poland

${ }^{3}$ The Houston Methodist Research Institute, Houston, TX, USA

${ }^{4}$ Department of Surgery, The Houston Methodist Hospital, Houston TX, USA

${ }^{5}$ University of Texas, MD Anderson Cancer Center, Houston TX, USA

${ }^{6}$ Univ Rennes, UMR 6290, Institute of Genetics and Development of Rennes, Cell Cycle

Group, Faculty of Medicine, F-35000 Rennes, France

${ }^{7}$ Laboratory of Regenerative Medicine and Cell Biology, Military Institute of Hygiene and Epidemiology (WIHE), Warsaw, Poland

Corresponding author:

Rafal P. Piprek

Department of Comparative Anatomy

Institute of Zoology and Biomedical Research

Jagiellonian University

Gronostajowa 9

30-387 Krakow, Poland

Phone: +48126645059

e-mail: rafal.piprek@uj.edu.pl 


\begin{abstract}
Development of the gonads is a complex process, which starts with a period of undifferentiated, bipotential gonads. During this period the expression of sex-determining genes is initiated. Sex determination is a process triggering differentiation of the gonads into the testis or ovary. Sex determination period is followed by sexual differentiation, i.e. appearance of the first testis- and ovary-specific features. In Xenopus laevis W-linked DMdomain gene $(D M-W)$ had been described as a master determinant of the gonadal female sex. However, the data on the expression and function of other genes participating in gonad development in $X$. laevis, and in anurans, in general, are very limited. We applied microarray technique to analyze the expression pattern of a subset of $X$. laevis genes previously identified to be involved in gonad development in several vertebrate species. We also analyzed the localization and the expression level of proteins encoded by these genes in developing $X$. laevis gonads. These analyses pointed to the set of genes differentially expressed in developing testes and ovaries. Gata4, Sox9, Dmrt1, Amh, Fgf9, Ptgds, Pdgf, Fshr, and Cyp17a1 expression was upregulated in developing testes, while DM-W, Fst, Foxl2, and Cyp19a1 were upregulated in developing ovaries. We discuss the possible roles of these genes in development of $X$. leavis gonads.
\end{abstract}

Keywords: gonad; testis; ovary; sex determination; gonad development; Xenopus 
Abbreviations: Amh - Anti-Müllerian hormone; Bmp4 - Bone morphogenetic protein 4; Dax1 - Dosage-sensitive sex reversal; adrenal hypoplasia critical region, on chromosome X, gene 1; Dhh - Desert hedgehog; Dmrt1 - Doublesex and mab-3 related transcription factor 1; DM-W - W-linked DM-domain gene; Emx2 - Empty Spiracles Homeobox 2; Fgf9 Fibroblast growth factor 9; Fgfr2 - Fibroblast growth factor receptor 2; Foxl2 - Forkhead Box L2; Fst - Follistatin; Gata4 - GATA binding protein 4; Inhb - Inhibin; Nr5a1 - Nuclear receptor 5a1; Pdgf - Platelet-derived growth factor; Pdgfr $\alpha$ - Platelet-derived growth factor receptor $\alpha$; Ptch1 - Patched 1; Ptgds - Prostaglandin D synthase; Rspo1 - R-spondin 1; Sf1 Steroidogenic factor 1; Sox - SRY-box; StAR - Steroidogenic acute regulatory protein; Wnt4 - Wingless-Type MMTV Integration Site Family, Member 4; Wt1 - Wilms tumor 1

\section{Introduction}

At the earliest phase of development, the Xenopus laevis gonads are sexually undifferentiated and bipotential, thus they can differentiate into testes or ovaries depending on the genetic/chromosomal background: ZW in female and ZZ in male. In anuran amphibians the gonads appear around the hindlimb buds stage. In Xenopus laevis tadpole the period of undifferentiated gonad falls between Nieuwoop and Faber (NF) stage 49 and 53 (Piprek et al. 2017) (Fig. 1A), and the crucial sex-determining period occurs between stage NF50 and 52, when the W-linked DM-domain $(D M-W)$ transcription factor starts being expressed in the ZW (genetic female) gonads (Yoshimoto et al. 2008). The DM-W, by blocking the Doublesex and mab-3 related transcription factor 1 (DMRT1), which participates in male sex determination in vertebrates, induces female pathway (Yoshimoto et al. 2010). Interaction between these two genes triggers a series of changes leading to the development of testis- or ovary-specific features. The sex-determining period is followed by the period of sexual differentiation of the 
gonads. In $X$. laevis, the first differences between male and female gonads are identifiable at stage NF53, when the germ cells start dispersing within the differentiating testes, while remaining at the gonad periphery in the ovaries (Piprek et al. 2017). At stage NF56 the gonadal sex becomes anatomically recognizable; the ovary consists of the central cavity surrounded by the cortex and sterile medulla, while in the developing testes the cortex and medulla fuse in a single cell mass without the cavity. Around metamorphosis (stage NF62) the gonads are visibly differentiated, the oocytes appear in the ovaries, and the sex cords (the future seminiferous tubules) form in the testes.

$X$. laevis is the only amphibian species in which the sex-determining gene has been discovered. However, surprisingly, the expression of only few genes such as Sox3 (Koyano et al. 1997), Dmrt1 (Osawa et al. 2005) and DM-W (Yoshimoto et al. 2008) had been studied in developing $X$. laevis gonads. The expression of Sox9 was studied in closely related Silurana tropicalis (El Jamil et al. 2008). Interestingly, there are many studies on the gene expression pattern in developing gonads of another anuran species, the Glandirana rugosa (reviewed in Nakamura 2009). G. rugosa is widely studied because of its unusual pattern of sex determination; both $\mathrm{XX} / \mathrm{XY}$ and $\mathrm{ZZ/ZW}$ system are present in different populations of this species (Nishioka et al. 1994).

In order to identify genes involved in gonad development and sex determination in $X$. laevis, we studied the expression of genes that are known to be involved in gonad development in other vertebrates. Considering a high number of genes of interest, we used a microarray to perform a global analysis of $X$. laevis transcriptome. We also performed the immunolocalization of proteins encoded by the chosen genes. The level of RNA and protein expression was analyzed at four time points: stage NF50 (undifferentiated gonad), NF53 (the onset of sexual differentiation), NF56 (differentiating gonads), and NF62 (sexually differentiated gonads) (Fig. 1). 


\section{Material and Methods}

\section{Animals}

Larvae of the African clawed frog (Xenopus laevis Daudin, 1802; Pipidae) were raised in the laboratory. The tadpoles were kept in $10-\mathrm{L}$ aquaria (30 tadpoles per $10 \mathrm{~L}$ ) at $22^{\circ} \mathrm{C}$ and fed daily with powder food Sera Micron (Sera) as previously described (Piprek et al. 2017). The tadpoles were staged according to Nieuwkoop and Faber (1964). After staging, the tadpoles at four stages (NF50, NF53, NF56, and NF62) were anesthetized with $0.1 \%$ MS222 solution. All specimens used in the experiments were handled according to Polish legal regulations concerning the scientific procedures on animals (Dz. U. nr 33, poz. 289, 2005) and the permission from the First Local Commission for Ethics in Experiments on Animals.

\section{Sex determination by PCR}

The genetic sex of each tadpole was determined using PCR detection of femalespecific DMW gene. DNA was isolated from tadpole tails using NucleoSpin Tissue Kit (Macherey-Nagel, 740952.240C). DMW gene (W-linked female-specific marker) and Dmrt1 gene (positive control) were used to determine ZZ or ZW status of tested animals. PCR was performed as previously described (Piprek et al. 2017). The mixture of the following pairs of primers were used: for DMW: 5'-CCACACCCAGCTCATGTAAAG-3' and 5'-

GGGCAGAGTCACATATACTG-3', and for Dmrt1: 5'-AACAGGAGCCCAATTCTGAG3' and 5'-AACTGCTTGACCTCTAATGC-3'

\section{Immunohistochemistry}

Bouin's solution-fixed and paraffin-embedded samples were serially sectioned at $4 \mu \mathrm{m}$. Sections were deparafinated, rehydrated and heat-induced epitope retrieval was performed in sodium citrate buffer (10 mM sodium citrate, $0.05 \%$ Tween-20, $\mathrm{pH}$ 6) at $95^{\circ} \mathrm{C}$ for $20 \mathrm{~min}$. (Piprek et al. 2017). Sections were blocked with 3\% $\mathrm{H}_{2} \mathrm{O}_{2}$ for 10 min., blocked in 6\% Bovine Serum Albumin (BSA, Sigma) for 15-min and incubated with the custom primary antibodies: 
anti-RSPO1 (GenScript, 674196-52), anti-WNT4 (GenScript, 674196-25), anti- $\beta$-catenin (GenScript, 674196-35), and anti-SOX9a (GenScript, 674196-42) at RT. UltraVision Quanto Detection System (ThermoFisher, TL-125-QHD) was used to visualize reaction and Mayer’s hematoxylin was used as a counterstain. Sections were viewed under Nikon Eclipse E600 microscope.

\section{RNA isolation}

Total RNA was isolated using Trizol as described above and further purified with Direct-zol RNA kit according to manufacturer’s protocol (Zymo Research, R2061). The total RNA eluted with RNase-free water was quantified with NanoDrop 2000, and RIN (RNA Integrity Number) was assessed using Bioanalyzer 2100. All specimens used in the study had RIN above 8. Total RNA in RNase-free water was frozen at $-80^{\circ} \mathrm{C}$ until further use.

\section{Microarray analysis}

The microarray experiment was repeated three times. In order to obtain sufficient amount of RNA, the samples from 10 individuals were pooled in each experiment. Total RNA was labeled with Cy3 using Agilent One-Color Quick Amp Labeling Protocol. Fluorescently labeled RNA samples were combined with Agilent Hi-RPM Hybridization Buffer, and hybridized at $65^{\circ} \mathrm{C}$ for 17 hours in HybArray 12 hybridization station (Perkin Elmer), then were washed for 1 minute each in Gene Expression Wash Buffer 1 (6X SSPE, 0.005\% Nlauroylsarcosine; at RT) and Gene Expression Wash Buffer (0.06X SSPE, 0.005\% Nlauroylsarcosine; at RT) for 1 minute each, immersed in a solution of acetonitrile and air dried. Slides (custom-commercial Agilent-070330 X. laevis Microarray slides) were scanned in Agilent Technologies G2505C Microarray Scanner at 5 $\mu \mathrm{m}$ resolution.

\section{Data processing}

TIF files from microarray scanner were processed using Agilent Feature Extraction software version 10.5.1.1. Control features and non-uniform features were removed, and 
remaining values for each unique probe sequence were averaged, then log (base 2)

transformed. Log base 2 intensities were median centered between arrays. Differential gene expression was filtered using both a statistical significance threshold (FDR $<0.05$ ) and a Fold Change threshold (1.5 fold). The data are available in Gene Expression Omnibus (accession number GSE105103) and in Suppl. Table 1.

\section{Results and Discussion}

Our transcriptional analysis allowed identification of genes that are sex-dimorphically expressed in developing gonads and thus are potentially involved in the control of gonad development. At stage NF50 none of the 46 analyzed genes showed sexual dimorphism in the expression pattern. This is not surprising because at this stage the gonads are still bipotential.

In the mouse Wt1, Sf1, Gata4 and Emx2 genes control the earliest phase of bipotential gonad development (reviewed by Piprek et al. 2016). These four transcription factors are expressed in the mouse genital ridges, they regulate the expression of mouse sex-determining genes, and their mutations lead to gonadal dysgenesis (Hammes et al. 2001; Luo et al. 1994; Miyamoto et al. 1997; Miyamoto et al. 2008). We chose $X$. laevis orthologs of these genes for our analysis. Because $X$. laevis is allotetraploid, some of its genes have two paralogs, a and b (Hughes and Hughes 1993). For the Wt1 gene (Wilms tumor 1) we studied the expression of two paralogs: Wt1a and Wt1b. Both showed only moderate difference in the expression between sexes, with slight tendency to increase from stage NF53 onward in the developing testes (Fig. 2). At stage NF62 the level of Wt1a and Wt1b expression slightly increased in the testes and decreased in the ovaries. A very similar pattern of expression was revealed for Nr5a1 (Sf1) and Gata4 with the highest level of expression in the testes (Fig. 2). The expression of $E m x 2$ (empty spiracles homeobox 2) was slightly higher in the ovaries (Fig. 2). The review of literature on the expression of above genes in other anurans showed that the expression of Wt1 was studied only in the frog Glandirana rugosa during early sexual 
differentiation of the gonads where no sex dimorphism in Wt1 expression was detected (Yamamura et al. 2005). The Nr5a1 was found to be upregulated in differentiating ovaries of Lithobates catesbeianus (Mayer et al. 2002), and was expressed in the adult testes but not in the ovaries of G. rugosa (Kawano et al. 2001). A participation of these genes in early gonad development may be conserved among vertebrates, for example Nr5a1 and Wt1 are expressed at early stages of gonad development in medaka, zebrafish, slider Trachemys scripta, American alligator and chicken (Spotila and Hall 1998; Western et al. 2000; Jorgensen et al. 2008; Kluver et al. 2009).

\section{Genes involved in female sex determination}

$D M-W$ (DM domain gene on $\mathrm{W}$ chromosome) transcription factor was identified as a master determiner of the female sex in X. laevis (Yoshimoto et al. 2008). The DM-W probably inhibits DMRT1 action, and thus blocks male sex determination (Yoshimoto et al. 2010). These researchers used RT-PCR to show that $D M-W$ gene was expressed only at the very early stage (NF48-50) of gonad development, and its expression ceased at stage NF52 (Yoshimoto et al. 2008). We detected strong expression of $D M-W$ throughout the ovarian development with a gradual increase from stage NF50 onward, and peaking at stageNF56 (Fig. 3). At stage NF62 the expression level of $D M-W$ decreased to the level comparable to

NF53. The difference between our and Yoshimoto et al. (2008) data may result from different method of analysis (microarray versus PCR) or different strains of X. laevis used.

In the mouse and human, the Rspo1 and Wnt4 gene products acting through $\beta$-catenin stabilization are pivotal for the female sex determination (Vainio et al. 1999; Parma et al. 2006; reviewed by Piprek 2010). We studied the expression of Rspo1, Wnt4 and Ctnnb1 ( $\beta$ catenin) in X. laevis gonads. The expression of Rspo1 was slightly higher in the female than in male gonad at stage NF56 (Fig. 3). Wnt4 and Ctnnb1 expression did not reveal significant sex 
difference (Fig. 3). The expression of Wnt4 gradually increased and peaked at stage NF56. To verify the potential role of these genes in gonad development we performed immunolocalization of proteins encoded by these three genes. Immunolocalization showed that WNT4 protein had strongest expression at stage NF56, which agreed with the results of microarray analysis (Fig. 4). No significant sex dimorphism was detectable in the expression of WNT4 protein. The RSPO1 protein, similar to RNA, had slightly stronger expression in the ovaries (Fig. 5). The expression level of Ctnnb1 gene was similar in both sexes. Immunolocalization of $\beta$-catenin showed sex dimorphism with the higher expression in the ovaries (Fig. 6), The higher level of $\beta$-catenin protein in developing ovaries in $X$. laevis might result from the $\beta$-catenin stabilization rather than the upregulation of its expression. This mechanism may be a conserved pathway of female sex determination among vertebrates because upregulation of Rspo1 expression at early stage of ovary development is characteristic not only for mouse and $X$. laevis but also for zebrafish, chicken and slider $T$. scripta (Smith et al. 2008; Zhang et al. 2011).

Foxl2 (forkhead box L2) encodes a transcription factor, which in developing mouse ovaries plays a role in female sex determination; its deletion leads to the expression of the male sex-determining genes (Ottolenghi et al. 2005). This gene is upregulated also in the developing ovaries in rainbow trout, slider T. scripta, chicken, and goat (Pailhoux et al. 2001; Loffler et al. 2003; Baron et al. 2004; Smith et al. 2008). In X. laevis, there was gradual upregulation of Foxl2 in the ovaries between stage NF50 and NF62 (Fig. 7). Foxl2 was also expressed in the testes but at lower level. Several studies showed that Foxl2 was upregualted in developing ovaries of Lithobates silvaticus, Silurana tropicalis and G. rugosa (NavaroMartin et al. 2012; Oshima et al. 2008). Thus, Foxl2 may play a similar role in ovary development in all anurans. 
Follistatin (encoded by Fst gene) is an autocrine glycoprotein, which binds and bioneutralizes members of the TGF- $\beta$ superfamily, and as a result inhibits formation of malespecific features, such as development of the coelomic vessels, in developing mouse ovaries (Yao et al. 2004). Fst has not been studied in the gonad development in amphibians. Here, for the first time we showed that Fst is significantly upregulated in $X$. laevis ovaries, between stage NF50 and NF62, while it is expressed at very low level in testes (Fig. 7). This suggests that follistatin may be also involved in the inhibition of the male pathway in developing ovaries of anurans.

Bmp4 is involved in ovary development by promoting ovarian follicles formation in the mouse (Nilsson and Skinner 2003). X. laevis Bmp4 (encoding bone morphogenetic protein 4) has two paralogs: Bmp4a and Bmp4b. We found that these two paralogs were expressed in the developing $X$. laevis gonads, however, with no significant sex-specific difference (Fig. 7). The Dax1 gene, which encodes nuclear receptor, is slightly upregulated in the testes at stage

NF62 in X. laevis (Fig. 7). The upregulation of this gene in developing testes was also showed for another anuran, G. rugosa (Sugita et al. 2001). In contrast, the expression of Dax1 was downregulated during testes development in the mouse and chicken (Smith et al. 2000; Swain et al. 1996), which indicates functional difference of this gene among vertebrates. In the mice mutation of Dax1 leads to male-to-female sex reversal due to inhibition of Sox9 gene - a key player in male sex determination pathway (Bouma et al. 2005).

\section{Genes involved in male sex determination}

Dmrt1 (encoding doublesex and mab-3 related transcription factor 1) is an evolutionary conserved gene playing a role in male sex determination in vertebrates (Koopman and Loffler 2003). Its mutation leads to male-to-female sex reversal. In X. laevis two paralogs: Dmrt1a and Dmrt1b are present. Both showed a very strong expression in the 
testes from the early phase of male gonad development (NF53) (Fig. 8). Dmrt1 expression in developing testes, but not ovaries was previously shown in G. rugosa and X. laevis (Osawa et al. 2005; Shibata et al. 2002).

A signaling factor FGF9 (fibroblast growth factor 9) acting via FGFR2 (fibroblast growth factor receptor 2) participates in a male sex determination in the mouse and enhances cell proliferation, which is critical for testis development (Kim et al. 2006). In developing $X$. laevis gonads the Fgf9 and Fgfr2 show visible sex-specific difference in expression around metamorphosis (stage NF62) with prevalence in the male gonads (Fig. 8). This suggests that FGF9/FGRF2 pathway is involved in some aspects of testis development in $X$. laevis. In contrast, in developing gonads of $G$. rugosa there is no sex-specific difference in the expression of these genes (Yamamura et al. 2005). We also analyzed the expression of gene coding for FGFR3 receptor, which seems to be important in chicken ovary development (Ayers et al. 2015). In X. laevis, the expression of Fgfr3 showed highly significant sexspecific difference at stage NF62, with the higher expression in the male gonad (Fig. 8).

Prostaglandin D2 (PGD2) is a signaling molecule, which enhances expression of genes involved in male sex determination in the mouse (Malki et al. 2005; Wilhelm et al. 2007). In $X$. laevis, the expression of prostaglandin synthase Ptgds- $a$ gene was slightly higher in the testes than in the ovaries (Fig. 8). The expression of the other paralogue of prostaglandin synthase, the Ptgds- $b$, showed strong upregulation in $X$. laevis male gonads from stage NF53 onward (Fig. 8). This indicates that prostaglandin signaling is probably involved in male sex determination and/or testis development in X. laevis.

\section{Sox genes}

We studied the expression of seven Sox genes that are known to participate in the gonad development in vertebrates. Among them SOX9 transcription factor is upregulated in 
developing testes, and plays a main role in male sex determination in many vertebrates (Koopman 2001). We found that Sox9a and Sox9b (Sry-box 9) paralogs were significantly upregulated in $X$. laevis testes (Fig. 9). Sox9a was gradually upregulated in testes and ovaries. We observed a significant upregulation of Sox9a expression in the testes between stage NF53 and NF62. The expression of Sox9b was higher in the testes than in the ovaries, but in contrast to Sox9a, there was no upregulation after stage NF53. These results suggest a potential involvement of these two Sox9 paralogs in $X$. laevis testis development. Because of the particularly high difference in the expression levels of Sox9 between ovaries and testes we performed immunolocalization of SOX9a protein in developing $X$. laevis gonads. The intensity of SOX9a immunostaining gradually increased in the male gonads and was the highest at NF62 stage, which corroborated gene expression pattern (Fig. 10). This malespecific expression resembles the expression pattern of Sox9 in other vertebrates including mammals (Koopman 2001). There must be however some interspecific differences because in the G. rugosa frog the expression of Sox 9 was detected in both sexes, and the upregulation in the testes was observed two months after metamorphosis when the testes are already fully developed and differentiated (Takase et al. 2000).

Sox3 was expressed at low level in the early stages of $X$. laevis gonad development, however, was highly upregulated in the ovaries at stage NF62 (Fig. 9). Sox12 showed upregulation in the testes at stage NF56 and NF62 (Fig. 9). Paralog Sox18a was upregulated in the testes at stage NF62, while, Sox18b became upregulated earlier, at stage NF53, NF56 and NF62 also exclusively in the testes (Fig. 9). In summary, the upregulation of Sox9a, Sox9b, Sox18a, Sox18b, and Sox12 was characteristic for developing testis, however, Sox3 expression was characteristic for developing ovary. Previously, the expression of Sox3 in adult ovaries and Sox18 in adult testes was described in X. laevis (Hasewaga et al. 2002; 
Koyano et al. 1997). This indicates that for some Sox genes, the pattern of expression established during gonad development persists through the adulthood.

\section{Genes involved in testis development}

There is a subpopulation of genes involved in testis development in vertebrates (Piprek 2010). These genes become upregulated in the testes after sex-determining period. Among these genes $P d g f$ (encoding platelet derived growth factor) is responsible for cell proliferation, migration and testis cord formation in the mouse testis (Brennan et al. 2003). We found that the expression of Pdgfa and Pdgfb was upregulated in the developing testis in X. laevis in comparison to the ovaries. Pdgfa was expressed from stage NF53 with upregulation at stage NF62, and Pdgfb was upregulated in the testis later, at stage NF62 (Fig. 11). The gene encoding PDGF receptor ( $P d g f r \alpha$ ), was upregulated in the testes starting from stage NF53, and showed visible sex dimorphism especially at stage NF62. These data suggest the involvement of PDGF pathway in the formation of testis structure in anurans.

Desert hedgehog (Dhh) participates in the proliferation/survival of fetal Leydig precursors in the interstitium of the mouse testis and the formation of testis cords (Yao and Capel 2002; Yao et al. 2002). We detected a relatively low level of expression of its two paralogs Dhh- $a$ and Dhh- $b$ in X.laevis testes and ovaries with the higher expression level in the testes. The Dhh- $b$ had the strongest sex dimorphism of expression at stage NF56 and NF62. The Ptch1 (protein patched homolog 1), which encodes DHH receptor, was expressed in the developing $X$. laevis gonads with a higher level of expression in the testes (Fig. 11).

In mammals, the inhibin $\mathrm{B}$, a member of TGF $\beta$ family, is responsible for the formation of proper testis structure and its vasculature (Yao et al. 2006). We found that in $X$. laevis the genes encoding three inhibins were expressed in developing gonads (Fig. 11). Inhibin A gene (Inhba) was expressed both in testes and ovaries and was gradually upregulated in the testes 
between stage NF56 and NF62 (Fig. 11). Inhibin B gene (Inhbb) was upregulated also in the testes after NF56, while, inhibin C gene (Inhbc) was upregulated in the testes earlier, starting from stage NF53 onward. Another TGF $\beta$ member, the anti-Müllerian hormone (AMH) is a factor secreted by developing vertebrate testes, which promotes degeneration of Müllerian ducts (oviducts) in males. We studied the expression of $X$. laevis ortholog of Amh and found high expression of this gene in the male gonads from stage NF56 onwards (Fig. 11). So far, the upregulation of Amh gene in the developing anuran testes was shown only for S. tropicalis and G. rugosa (Jansson et al. 2016; Kodama et al. 2015), and in X. laevis using immunolocalization (Piprek et al. 2013). These data suggest AMH involvement in Müllerian ducts regression in amphibian males.

\section{Genes of steroidogenesis and other hormones signaling}

Next we focused on the expression pattern of genes involved in hormonal control of gonad development. Among genes encoding receptors of gonadotropins, the folliclestimulating hormone receptor gene (Fshr) was expressed both in testes and ovaries but was significantly upregulated in the testes starting from stage NF53 (Fig. 12). The luteinizing hormone receptor gene ( $L h r)$ did not reveal significant sex differences and was expressed at a very low level in the gonads of both sexes (Fig. 12). The expression of Fshr receptor implies a control of testis development by pituitary FSH hormone. Gene encoding steroidogenic acute regulatory protein (Star) that is responsible for the cholesterol transfer to the mitochondria, was expressed both in testes and ovaries but showed stronger expression in the testes at stage NF62 (Fig. 12). Cyp17a1 encodes cytochrome P450 17A1 that converts progestagens to androgens. We detected significant upregulation of this gene in the testes starting from stage NF53 (Fig. 12). This indicates that there is higher steroidogenic activity in developing testes than in the ovaries. The Cyp19a1 that encodes aromatase responsible for testosterone 
conversion to estradiol was expressed both in testes and ovaries but was strongly upregulated in ovaries starting from stage NF53. Its expression level in testes was much lower than in ovaries and slightly increased from NF53 onward (Fig. 12). This indicates that estradiol is probably synthesized in the developing ovaries from the onset of their differentiation. The Hsd3b1 encodes $3 \beta$-hydroxysteroid dehydrogenase, which is responsible for the synthesis of progesterone. The expression of this gene showed sex-specific differences only at stage NF62 with stronger expression in the testes and decreased expression in the ovaries (Fig. 12). The expression of Srd5a1, which encodes reductase that converts testosterone to dihydrotestosterone, did not show any significant sex dimorphism (Fig. 12). The androgen receptor-coding gene $(\mathrm{Ar})$ was expressed in developing ovaries and testes with strong upregulation in the testes at stage NF62 (Fig. 12). Genes of steroidogenesis were studied also in gonad development in G. rugosa. In this species the upregulation of Cyp17a1 and $\mathrm{Ar}$ occurred in developing testes, however, Cyp19a1 was upregulated in the ovaries (Iwade 2008; Kato 2004; Mauro 2008; Yokoyama 2009). Similar pattern of steroidogenic enzymes expression is also characteristic for other vertebrates such as zebrafish, T. scripta, American alligator, and chicken (Western et al. 2000; Jorgensen et al. 2008; Matsumoto et al. 2013; Shaikat et al. 2017).

\section{Conclusion}

Our study indicates that many genes belonging to various pathways are sexspecifically expressed and thus may be involved in the control of gonad development in $X$. laevis. We showed a significant sexual dimorphism in the expression of several genes. Summary of genes expressed at consecutive stages of gonad development is presented in Fig. 13. The Gata4, Sox9, Dmrt1, Amh, Fgf9, Ptgds, Pdgf, Fshr, and Cyp17a1 showed upregulation of expression in testes, while DM-W, Fst, Foxl2, and Cyp19a1 were upregulated 
in the ovary. An exact role of most of these genes in X. laevis gonad development remains unknown and further experimental studies with genetic or functional knockouts are necessary to identify the function of these genes.

\section{Acknowledgements}

The study was conducted within the project no 0372/IP1/2015/73 financed by Polish Ministry of Science and Higher Education in the program Iuventus Plus.

\section{References}

Ayers K.L., Lambeth L.S., Davidson N.M., Sinclair A.H., Oshlack A., Smith C.A., 2015. Identification of candidate gonadal sex differentiation genes in the chicken embryo using RNA-seq. BMC Genomics 16,704.

Baron D., Cocquet J., Xia X., Fellous M., Guiguen Y., Veitia R.A., 2004. An evolutionary and functional analysis of FoxL2 in rainbow trout gonad differentiation. J. Mol. Endocrinol. 33, 705-715.

Bouma G.J., Albrecht K.H., Washburn L.L., Recknagel A.K., Churchill G.A., Eicher E.M., 2005. Gonadal sex reversal in mutant Dax1 XY mice: a failure to upregulate Sox9 in preSertoli cells. Development 132, 3045-54.

Brennan J., Tilmann C., Capel B., 2003. Pdgfr- $\alpha$ mediates testis cord organization and fetal Leydig cell development in the XY gonad. Genes Dev. 17, 800-810.

El Jamil A., Kanhoush R., Magre S., Boizet-Bonhoure B., Penrad-Mobayed M., 2008. Sexspecific expression of SOX9 during gonadogenesis in the amphibian Xenopus tropicalis. Dev. Dyn. 237, 2996-3005.

Hammes A., Guo J.K., Lutsch G., Leheste J.R., Landrock D., Ziegler U., Gubler M.C., Schedl A., 2001. Two splice variants of the Wilms' tumor 1 gene have distinct functions during sex determination and nephron formation. Cell 106, 319-329.

Hasegawa M., Hiraoka Y., Hagiuda J., Ogawa M., Aiso S., 2002. Expression and characterization of Xenopus laevis SRY-related cDNAs, xSox17alpha1, xSox17alpha2, xSox18alpha and xSox18beta. Gene 290, 163-72.

Hughes M.K., Hughes A.L., 1993. Evolution of duplicate genes in a tetraploid animal, Xenopus laevis. Mol. Biol. Evol. 10, 1360-9.

Iwade R., Maruo K., Okada G., Nakamura M., 2008. Elevated expression of P450c17 (CYP17) during testicular formation in the frog. Gen. Comp. Endocrinol. 155, 79-87.

Jansson E., Mattsson A., Goldstone J., Berg C., 2016. Sex-dependent expression of antiMüllerian hormone (amh) and amh receptor 2 during sex organ differentiation and 
characterization of the Müllerian duct development in Xenopus tropicalis. Gen. Comp. Endocrinol. 229, 132-44.

Jorgensen A., Morthorst J.E., Andersen O., Rasmussen L.J., Bjerregaard P., 2008. Expression profiles for six zebrafish genes during gonadal sex differentiation. Reprod. Biol.

Endocrinol. 6, 25.

Kluver N., Herpin A., Braasch I., Driessle J., Schartl M., 2009. Regulatory back-up circuit of medaka Wt1 co-orthologs ensures PGC maintenance. Dev. Biol. 325, 179-88.

Kodama M., Suda M., Sakamoto D., Iwasaki T., Matsuo Y., Uno Y., Matsuda Y., Nakamura Y., Maekawa S., Katsu Y., Nakamura M., 2015. Molecular cloning and characterization of anti-Müllerian hormone (AMH) from the Japanese wrinkled frog, Rana rugosa.

Endocrinology 156, 1914-23.

Kato T., Matsui K., Takase M., Kobayashi M., Nakamura M., 2004. Expression of P450 aromatase protein in developing and in sex-reversed gonads of the XX/XY type of the frog Rana rugosa. Gen. Comp. Endocrinol. 137, 227-36.

Kawano K., Furusawa S., Matsuda H., Takase M., Nakamura M., 2001. Expression of steroidogenic factor-1 in frog embryo and developing gonad. Gen. Comp. Endocrinol. 123, $13-22$.

Kim Y., Kobayashi A., Sekido R., DiNapoli L., Brennan J., Chaboissier M.C., Poulat F., Behringer R.R., Lovell-Badge R., Capel B., 2006. Fgf9 and Wnt4 act as antagonistic signals to regulate mammalian sex determination. PLoS Biol. 4, e187.

Koopman P., 2001. Sry, Sox9 and mammalian sex determination. EXS. 2001, 25-56.

Koopman P., Loffler K.A., 2003. Sex Determination: The Fishy Tale of Dmrt1. Curr. Biol. 13, 177-9.

Koyano S., Ito M., Takamatsu N., Takiguchi S., Shiba T., 1997. The Xenopus SOX3 gene expressed in oocytes of early stages. Gene 188, 101-107.

Loffler K.A., Zarkower D., Koopman P., 2003. Etiology of ovarian failure in blepharophimosis ptosis epicanthus inversus syndrome: FOXL2 is a conserved, early-acting gene in vertebrate ovarian development. Endocrinology 144, 3237-3243 (2003).

Luo X., Ikeda Y., Parker K.L., 1994. A cell-specific nuclear receptor is essential for adrenal and gonadal development and sexual differentiation. Cell 77, 481-490.

Malki S., Nef S., Notarnicola C., Thevenet L., Gasca S., Mejean C., Berta P., Poulat F., Boizet-Bonhoure B., 2005. Prostaglandin D2 induces nuclear import of the sexdetermining factor SOX9 via its cAMP-PKA phosphorylation. EMBO J. 24, 1798-1809.

Maruo K., Suda M., Yokoyama S., Oshima Y., Nakamura M., 2008. Steroidogenic gene expression during sex determination in the frog Rana rugosa. Gen. Comp. Endocrinol. 158, 87-94. 
Matsumoto Y., Buemio A., Chu R., Vafaee M., Crews D., 2013. Epigenetic control of gonadal aromatase (cyp19a1) in temperature-dependent sex determination of red-eared slider turtles. PLoS One. 8(6), e63599.

Mayer L.P., Overstreet S.L., Dyer C.A., Propper C.R., 2002. Sexually dimorphic expression of steroidogenic factor 1 (SF-1) in developing gonads of the American bullfrog, Rana catesbeiana. Gen. Comp. Endocrinol. 127, 40-7.

Miyamoto N., Yoshida M., Kuratani S., Matsuo I., Aizawa S., 1997. Defects of urogenital development in mice lacking Emx2. Development 124, 1653-1664.

Miyamoto Y., Taniguchi H., Hamel F., Silversides D.W., Viger R.S., 2008. A GATA4/WT1 cooperation regulates transcription of genes required for mammalian sex determination and differentiation. BMC Mol. Biol. 9, 44.

Nakamura M., 2009. Sex determination in amphibians. Semin. Cell Dev. Biol. 20, 271-82.

Navarro-Martín L., Velasco-Santamaría Y.M., Duarte-Guterman P., Robertson C., Lanctôt C., Pauli B., Trudeau V.L., 2012. Sexing frogs by real-time PCR: using aromatase (cyp19) as an early ovarian differentiation marker. Sex. Dev. 6, 303-15.

Nilsson E.E., Skinner M.K., 2003. Bone morphogenetic protein-4 acts as an ovarian follicle survival factor and promotes primordial follicle development. Biol. Reprod. 69, 1265-72.

Nishioka M., Hanada H., Miura I., 1994. Four kinds of sex chromosomes in Rana rugosa. Sci. Rep. Lab. Amphibina Biol., Hiroshima Univ. 13, 1-34.

Osawa N., Oshima Y., Nakamura M., 2005. Molecular cloning of Dmrt1 and its expression in the gonad of Xenopus. Zoolog Sci. 22, 681-7.

Oshima Y., Uno Y., Matsuda Y., Kobayashi T., Nakamura M., 2008. Molecular cloning and gene expression of Foxl2 in the frog Rana rugosa. Gen. Comp. Endocrinol. 159, 170-177.

Ottolenghi C., Omari S., Garcia-Ortiz J.E., Uda M., Crisponi L., Forabosco A., Pilia G., Schlessinger D., 2005. Foxl2 is required for commitment to ovary differentiation. Hum. Mol. Genet. 14, 2053-62.

Pailhoux E., Parma P., Sundstrom J., Vigier B., Servel N., 2001. Time course of female-tomale sex reversal in 38,XX fetal and postnatal pigs. Dev. Dyn. 222, 328-340.

Parma P., Radi O., Vidal V., Chaboissier M.C., Dellambra E., Valentini S., Guerra L., Schedl A., Camerino G., 2006. R-spondin1 is essential in sex determination, skin differentiation and malignancy. Nat. Genet. 38, 1304-9.

Piprek, R.P., 2009. Molecular mechanisms underlying female sex determination—antagonism between female and male pathway. Folia Biol. 57, 105-113.

Piprek R.P., 2010. Molecular and cellular machinery of gonadal differentiation in mammals. Int. J. Dev. Biol. 54, 779-86. 
Piprek R.P., Pecio A., Laskowska-Kaszub K., Kubiak J.Z., Szymura J.Z., 2013. Sexual dimorphism of AMH, DMRT1 and RSPO1 localization in the developing gonads of six anuran species. Int. J. Dev. Biol. 57, 871-875.

Piprek R.P., Kloc M., Kubiak J.Z., 2016. Early Development of the Gonads: Origin and Differentiation of the Somatic Cells of the Genital Ridges. Results Probl. Cell Differ. 58, 122.

Piprek R.P., Kloc M., Tassan J.P., Kubiak J.Z., 2017. Development of Xenopus laevis bipotential gonads into testis or ovary is driven by sex-specific cell-cell interactions, proliferation rate, cell migration and deposition of extracellular matrix. Dev. Biol. 432, 298310.

Shaikat A.H., Namekawa S., Ahmadi S., Takeda M., Ohkubo T., 2017. Gene expression profiling in embryonic chicken ovary during asymmetric development. Anim. Sci. J. 2017 Dec 28. doi: 10.1111/asj.12979.

Shibata K., Takase M., Nakamura M., 2002. The Dmrt1 expression in sex-reversed gonads of amphibians. Gen. Comp. Endocrinol. 127, 232-41.

Smith C.A., Clifford V., Western P.S., Wilcox S.A., Bell K.S., Sinclair A.H., 2000. Cloning and expression of a DAX1 homologue in the chicken embryo. J. Mol. Endocrinol. 24, 23-32.

Spotila L.D., Hall S.H., 1998. Expression of a new RNA-splice isoform of WT1 in developing kidney-gonadal complexes of the turtle, Trachemys scripta. Comp. Biochem. Physiol. Part B. 119, 761-767.

Sugita J., Takase M., Nakamura M., 2001. Expression of Dax-1 during gonadal development of the frog. Gene 280, 67-74.

Swain A., Zanaria E., Hacker A., Lovell-Badge R., Camerino G., 1996. Mouse Dax1 expression is consistent with a role in sex determination as well as in adrenal and hypothalamus function. Nat. Genet. 12, 404-9.

Takase M., Noguchi S., Nakamura M., 2000. Two Sox9 messenger RNA isoforms: isolation of cDNAs and their expression during gonadal development in the frog Rana rugosa. FEBS Lett. 466, 249-54.

Western PS, Harry JL, Marshall Graves JA, Sinclair AH. 2000 Temperature-dependent sex determination in the American alligator: expression of SF1, WT1 and DAX1 during gonadogenesis. Gene 241, 223-32.

Wilhelm D., Hiramatsu R., Mizusaki H., Widjaja L., Combes A.N., Kanai Y., Koopman P., 2007. SOX9 regulates prostaglandin D synthase gene transcription in vivo to ensure testis development. J. Biol. Chem. 282, 10553-60.

Vainio S, Heikkilä M, Kispert A, Chin N, McMahon AP., 1999. Female development in mammals is regulated by Wnt-4 signalling. Nature 397, 405-9. 
Yamamura Y., Aoyama S., Oshima Y., Kato T., Osawa N., Nakamura M., 2005. Molecular cloning and expression in gonad of Rana rugosa WT1 and Fgf9. Zoolog. Sci. 22, 1045-50.

Yao H.H., Capel B., 2002. Disruption of testis cords by cyclopamine or forskolin reveals independent cellular pathways in testis organogenesis. Dev. Biol. 246, 356-65.

Yao H.H., Whoriskey W., Capel B., 2002. Desert Hedgehog/Patched 1 signaling specifies fetal Leydig cell fate in testis organogenesis. Genes Dev. 16, 1433-40.

Yao H.H., Matzuk M.M., Jorgez C.J., Menke D.B., Page D.C., Swain A., Capel B., 2004. Follistatin operates downstream of Wnt4 in mammalian ovary organogenesis. Dev. Dyn. 230, $210-5$.

Yao H.H., Aardema J., Holthusen K., 2006. Sexually dimorphic regulation of inhibin beta B in establishing gonadal vasculature in mice. Biol. Reprod. 74, 978-83.

Yokoyama S., Oshima Y., Tokita J., Suda M., Shinozuka T., Nakamura M., 2009. Androgen receptor of the frog Rana rugosa: molecular cloning and its characterization. J. Exp. Zool. A Ecol. Genet. Physiol. 311, 796-812.

Yoshimoto S., Okada E., Umemoto H., Tamura K., Uno Y., Nishida-Umehara C., Matsuda Y., Takamatsu N., Shiba T., Ito M., 2008. A W-linked DM-domain gene, DM-W, participates in primary ovary development in Xenopus laevis. Proc. Natl. Acad. Sci. U. S. A. 105, 246974.

Yoshimoto S, Ikeda N, Izutsu Y, Shiba T, Takamatsu N, Ito M., 2010. Opposite roles of DMRT1 and its W-linked paralogue, DM-W, in sexual dimorphism of Xenopus laevis: implications of a ZZ/ZW-type sex-determining system. Development 137, 2519-26.

Zhang Y., Li F., Sun D., Liu J., Liu N., Yu Q., 2011. Molecular analysis shows differential expression of R-spondin1 in zebrafish (Danio rerio) gonads. Mol. Biol. Rep. 38, 275-82.

\section{Figure legends}

Fig. 1. A. Diagram of gonad development in Xenopus laevis. At stage NF50 the gonads (arrowheads) are sexually undifferentiated and are composed of few germ cells (g) enclosed by somatic cells. The phase of undifferentiated gonads (between stage NF49 and NF53) has a sex determination sub-phase when sex-determining genes are expressed. Sexual differentiation follows this sub-phase. First sex differences are noticeable at NF53 when a medulla (arrow) forms in the centre of developing ovaries. At NF56 the ovaries are easily recognizable by the ovarian cavity (asterisk) present in the medulla, whereas the cavity is absent in the testes. At NF62 oocytes (o) are present in the ovaries, however, at this stage there are no meiotic cells in the testes.

B. Sexual differentiation and development of Xenopus laevis gonads at four time points. NF50 - undifferentiated gonad, NF53 - the onset of sexual differentiation, NF56 - differentiating gonads, and NF62 - gonads sexually differentiated. Scale bar $25 \mu \mathrm{m}$.

Fig. 2. Graphs of expression of Wt1, Nr5a1, Gata4, Emx2. 
Fig. 3. Graphs of expression of genes of female sex determination - DM-W, Wnt4, Rspo1, Ctnnb1.

Fig. 4. Immunohistochemistry of WNT4. Scale bar $25 \mu \mathrm{m}$.

Fig. 5. Immunohistochemistry of RSPO1. Scale bar $25 \mu \mathrm{m}$.

Fig. 6. Immunohistochemistry of $\beta$-catenin. Scale bar $25 \mu \mathrm{m}$.

Fig. 7. Graphs of expression of female sex determination genes: Foxl2, Fst, Bmp4, Dax1.

Fig. 8. Graphs of expression of male sex determining genes.

Fig. 9. Graphs of expression of Sox genes.

Fig. 10. Immunohistochemistry of SOX9a. Scale bar $25 \mu \mathrm{m}$.

Fig. 11. Graphs of expression of testis differentiation genes.

Fig. 12. Graphs of expression of steroidogenesis genes.

Fig. 13. Diagram of genes expressed at subsequent stages of $X$. laevis gonad development in both sexes. Sex-specifically upregulated genes are shown in bold.

Suppl. Table. 1. Microarray data of gene expression. M - male, F - female, FC - fold change. 
Fig. 1.

A

A sex determination

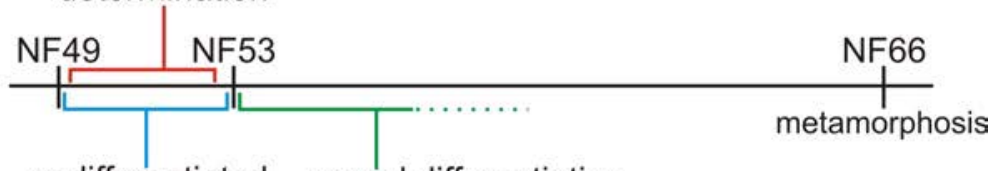

undifferentiated sexual differentiation gonads

B

$$
\text { Undifferentiated gonads }
$$

NF53
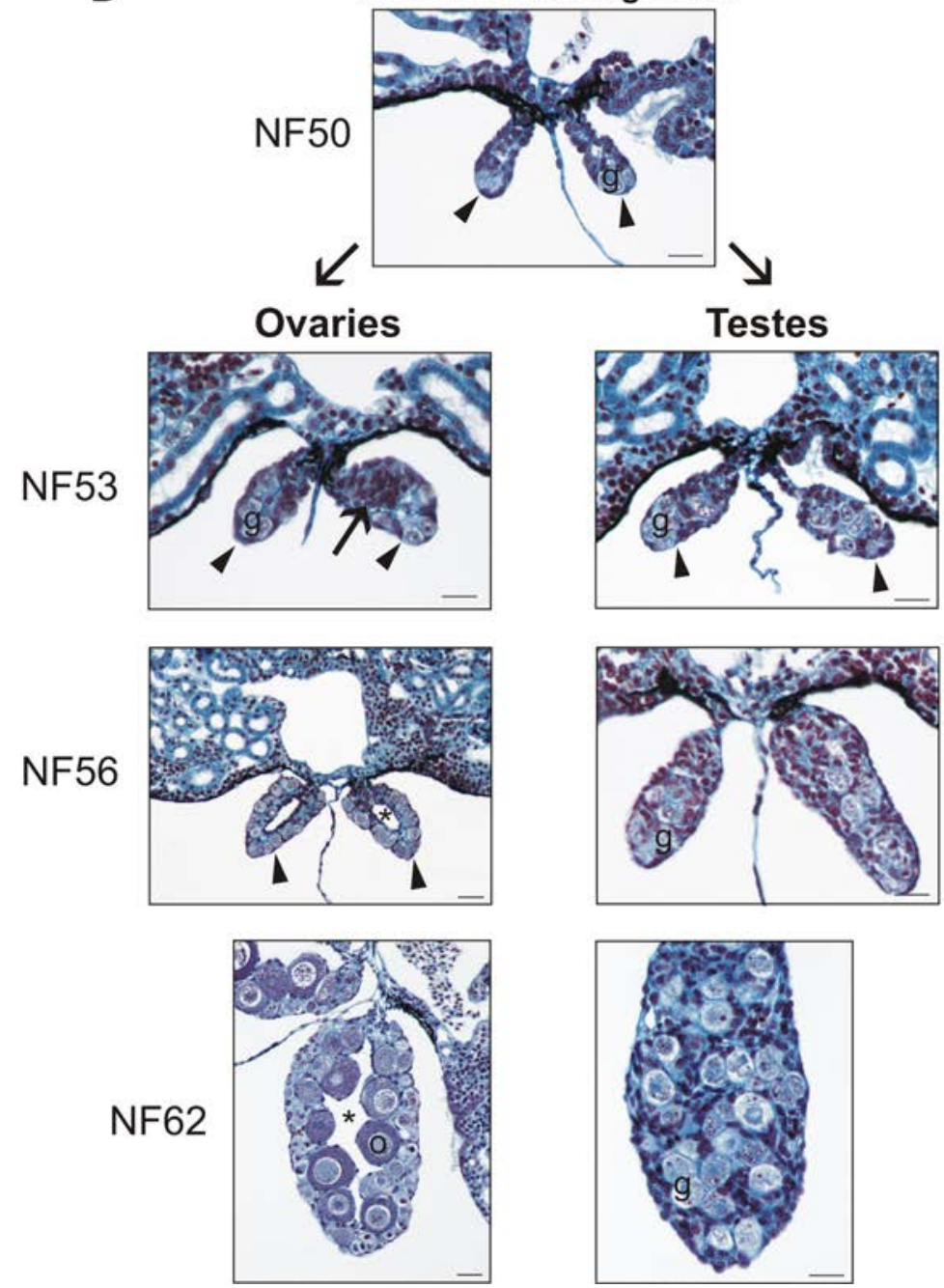
Fig. 2.
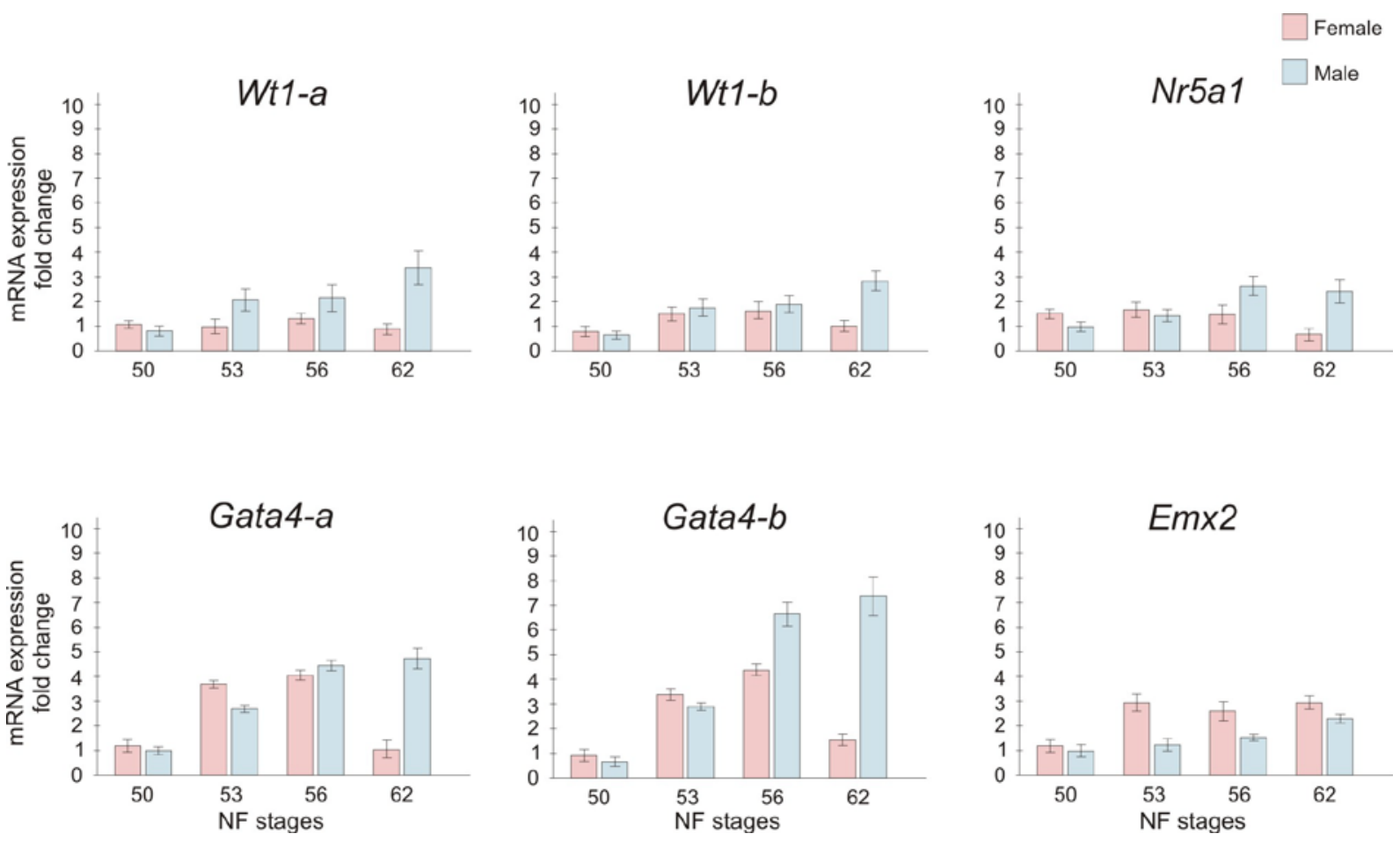

Fig. 3.
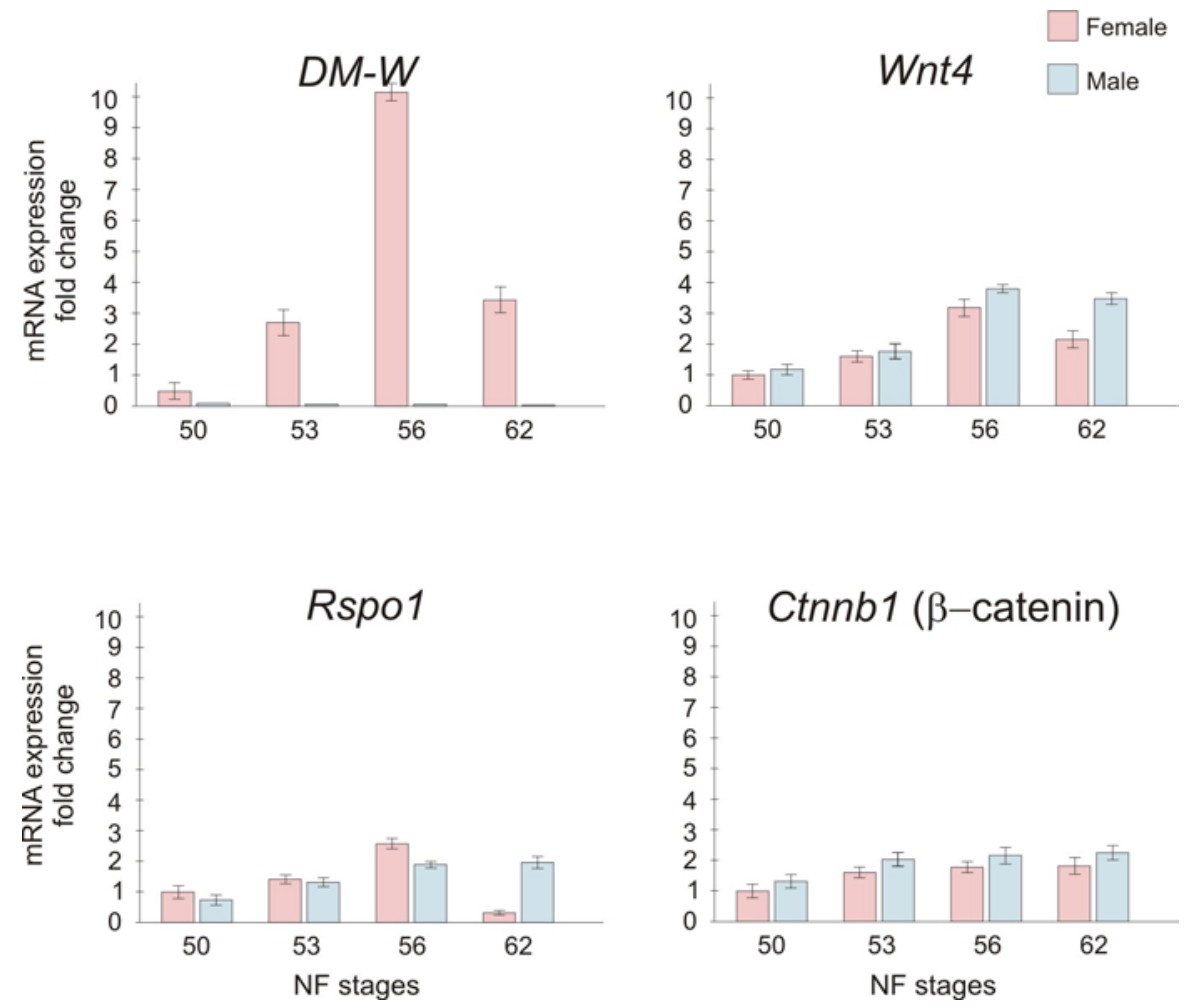
Fig. 4.
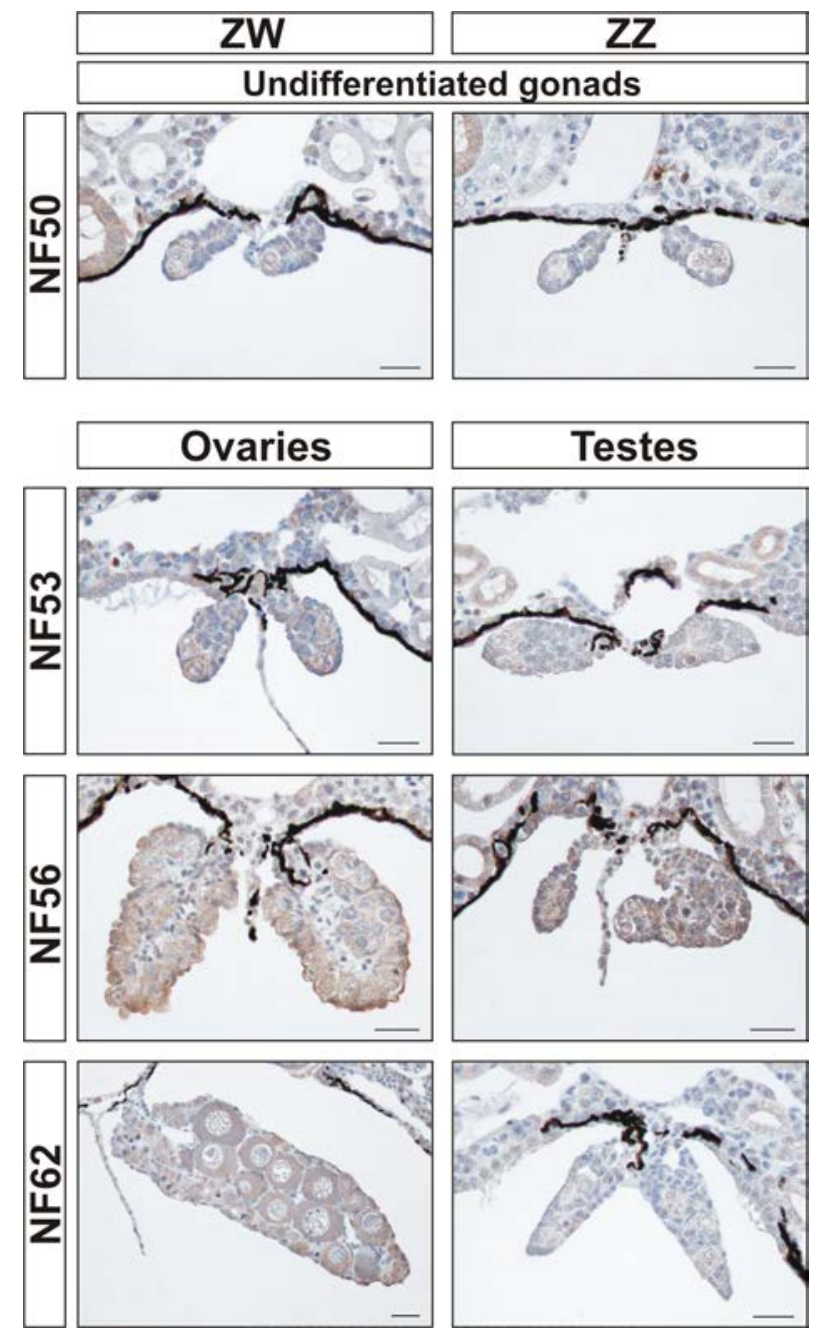
Fig. 5.
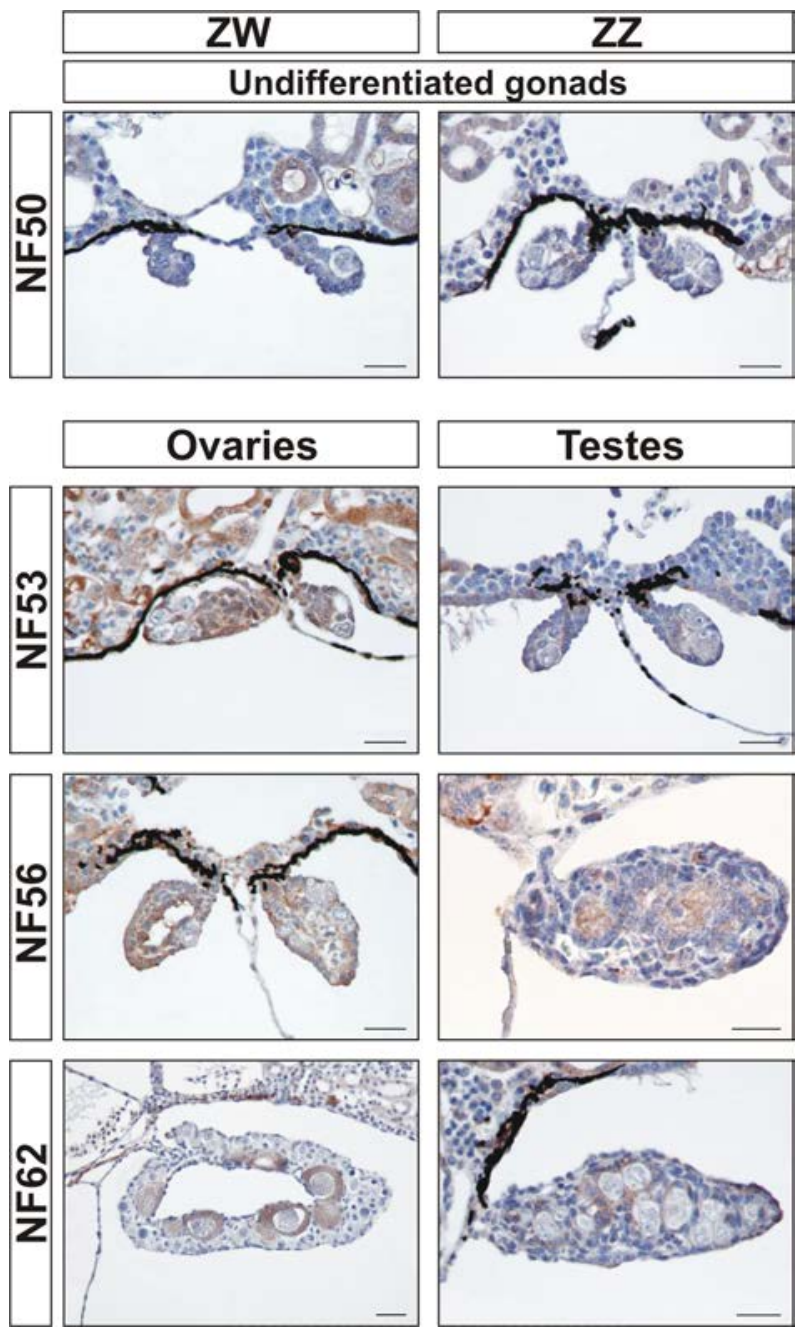
Fig. 6.
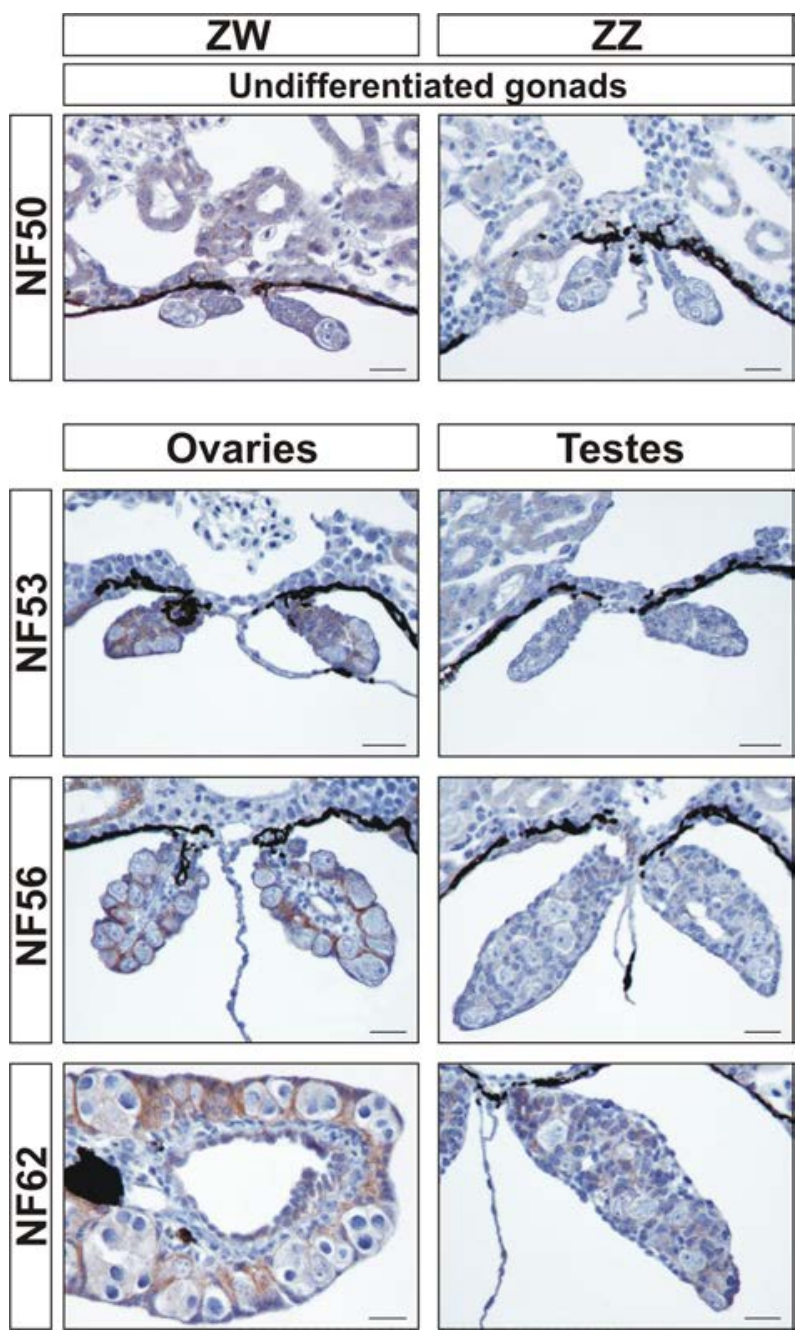
Fig. 7.
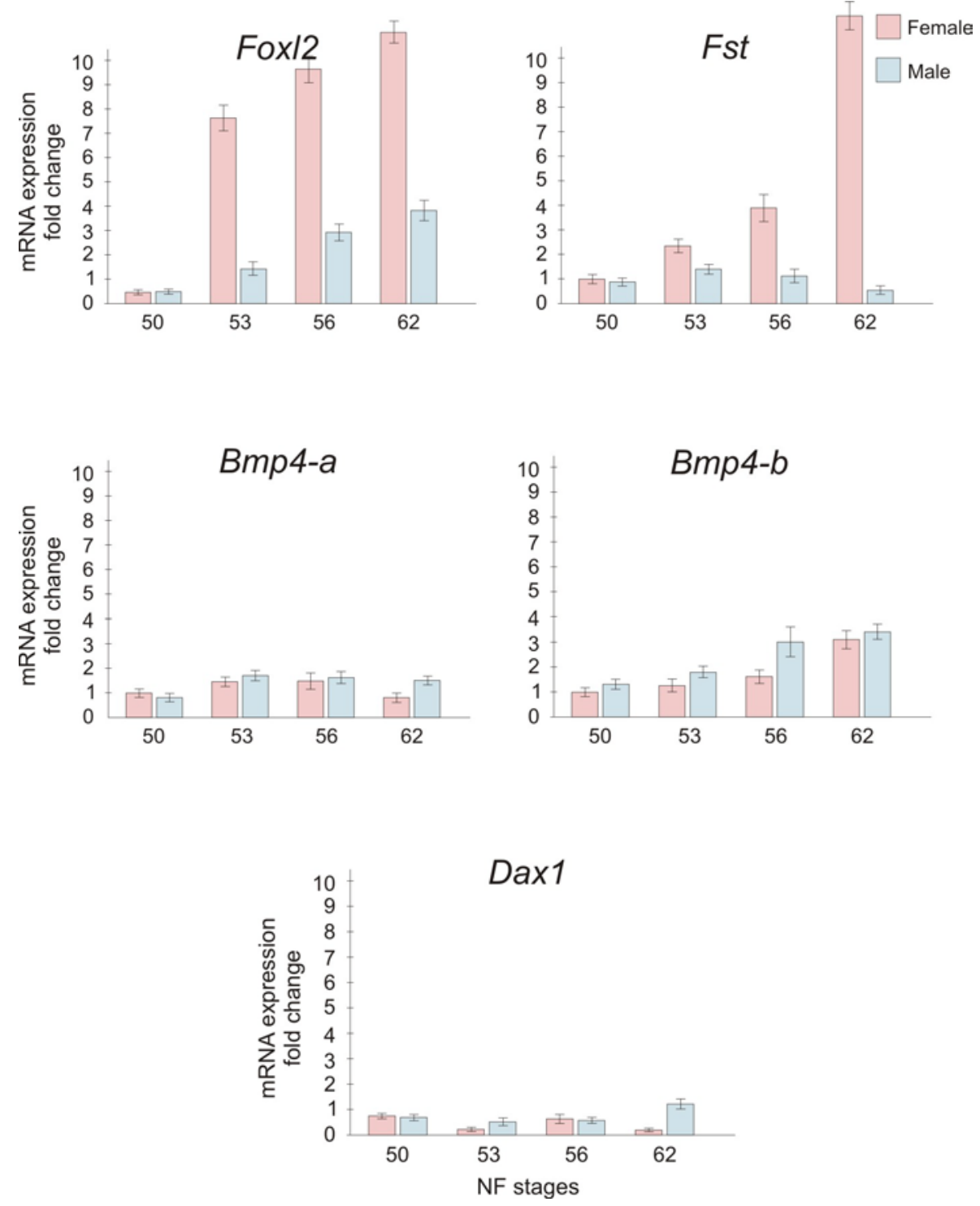
Fig. 8.
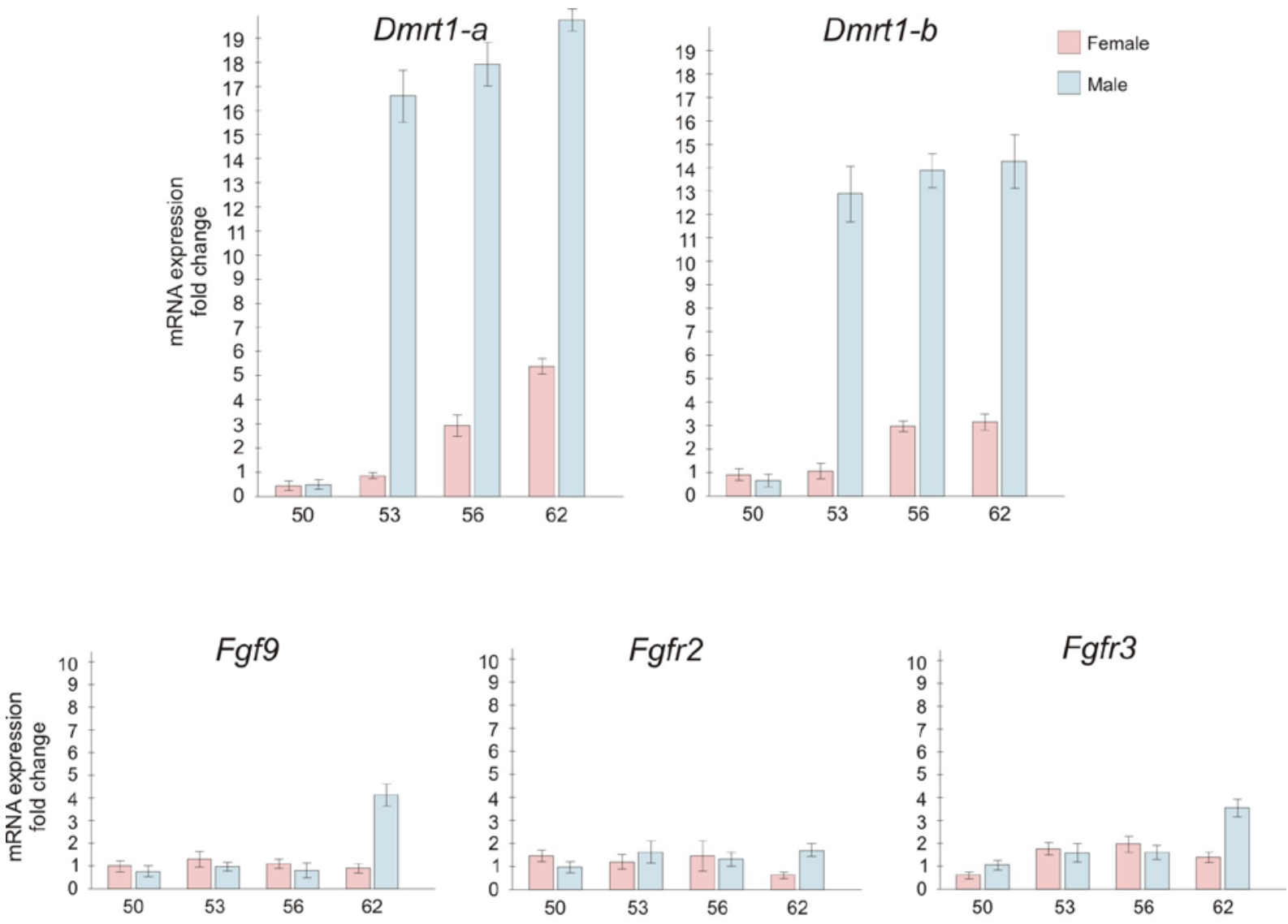

Ptgds-a
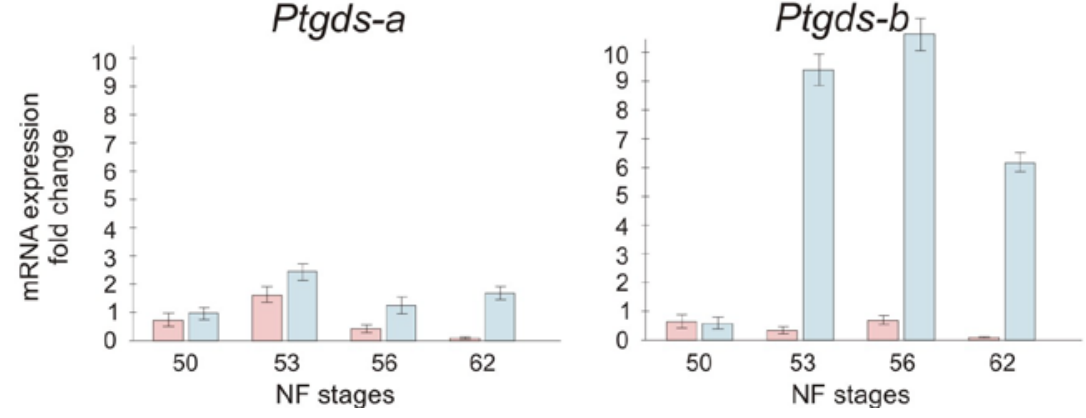
Fig. 9.

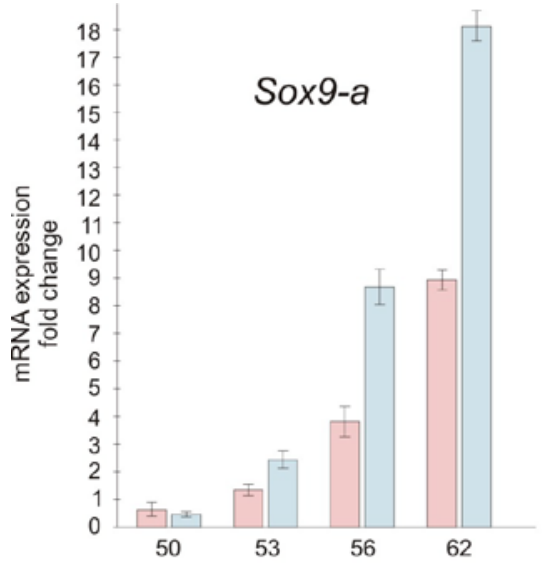

Sox9-b

Sox3 $\square$ Male
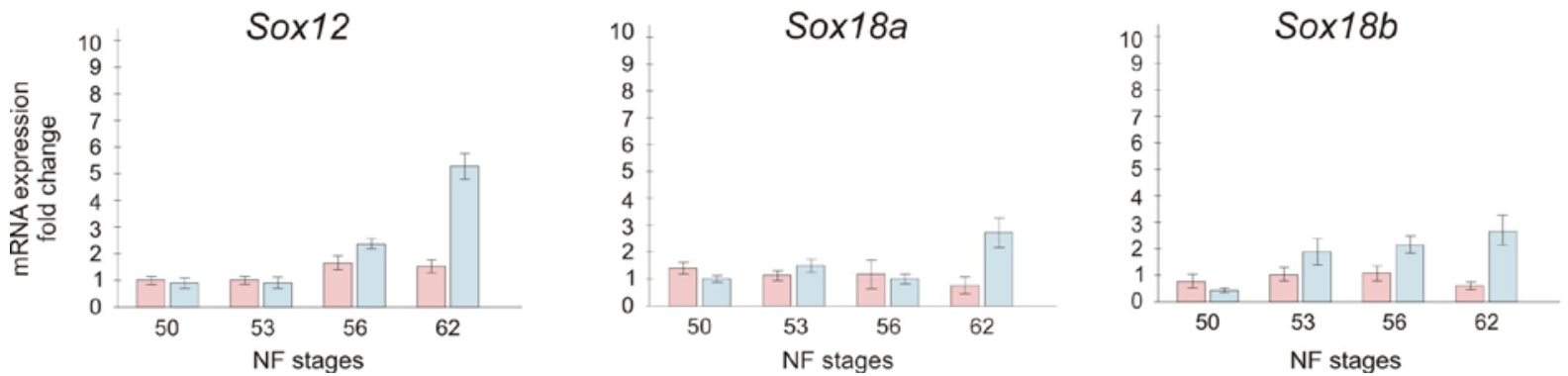
Fig. 10.
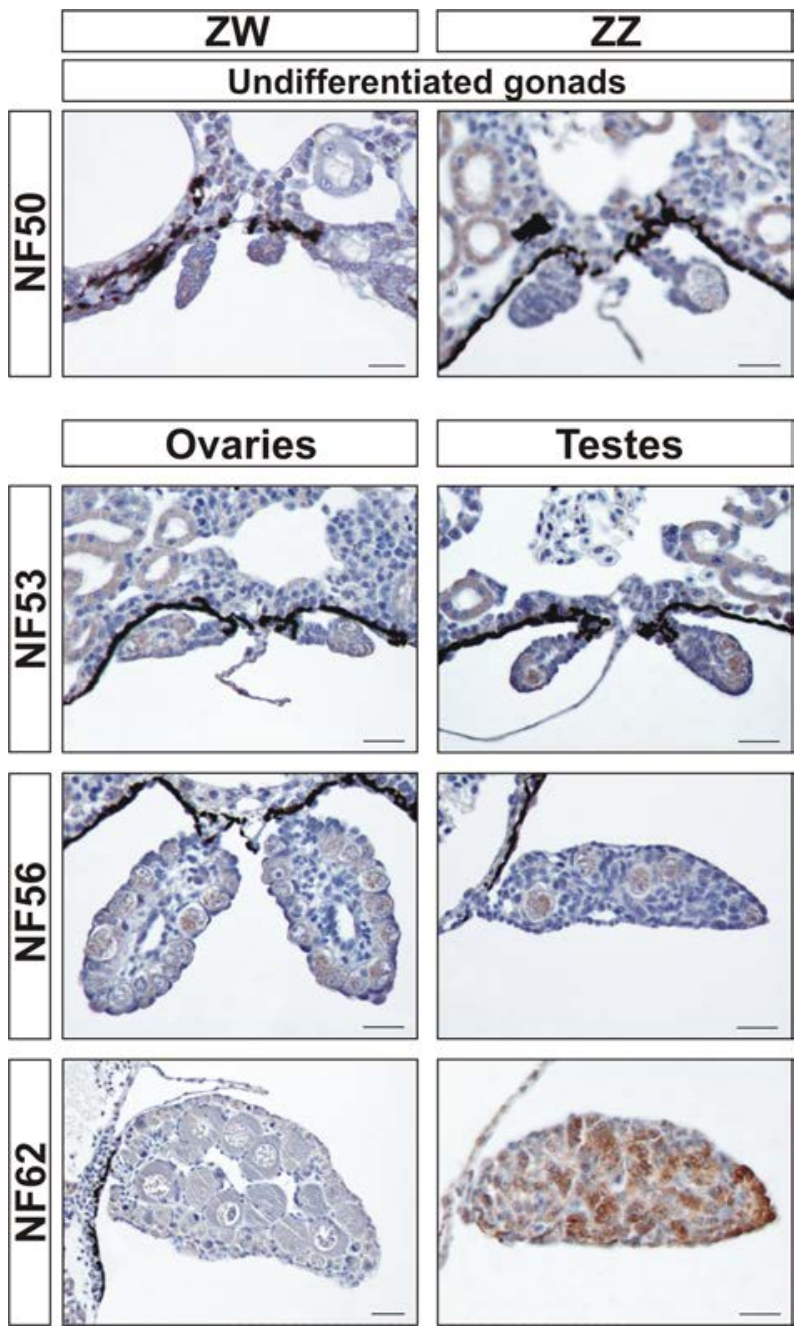
Fig. 11.
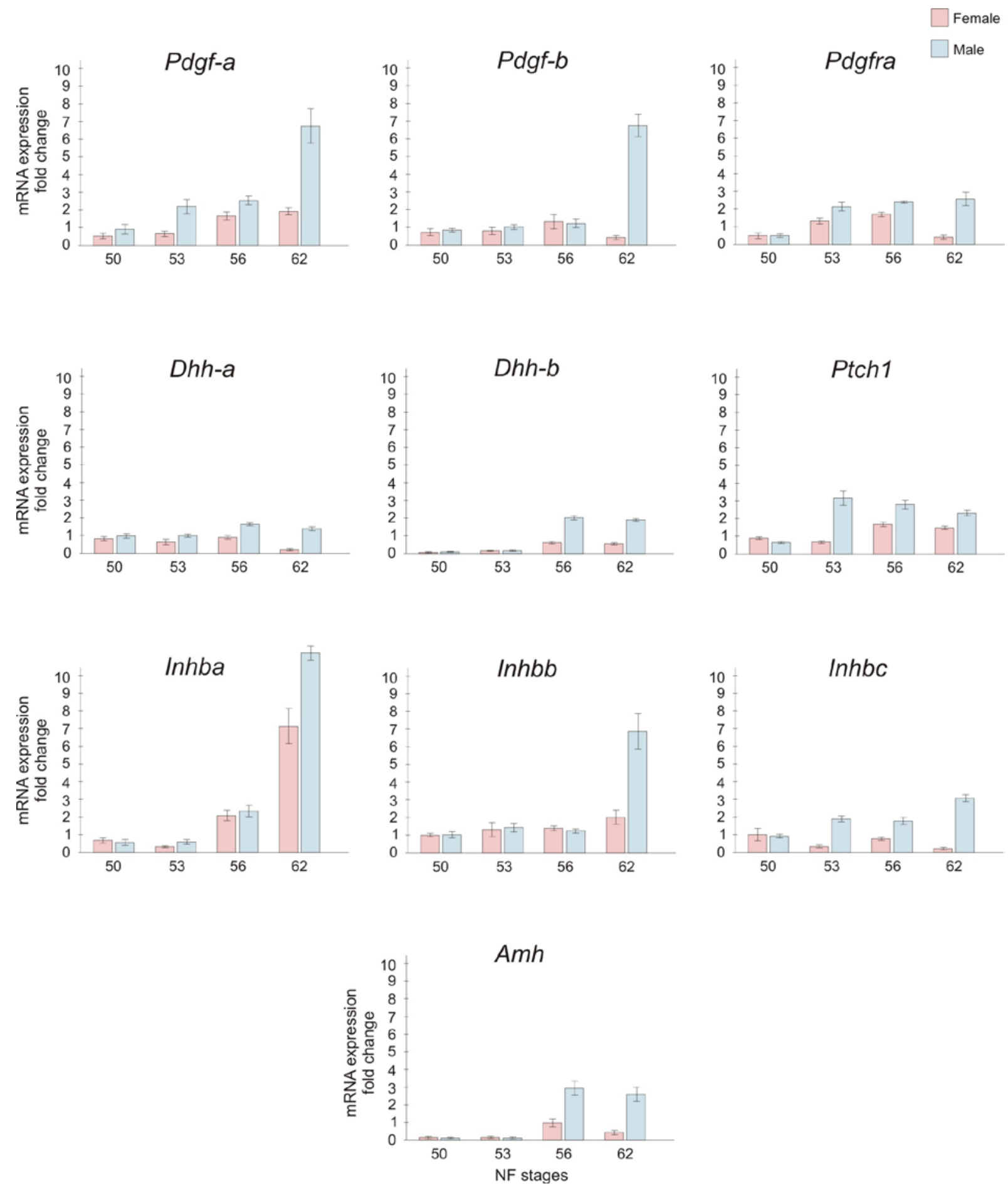
Fig. 12.
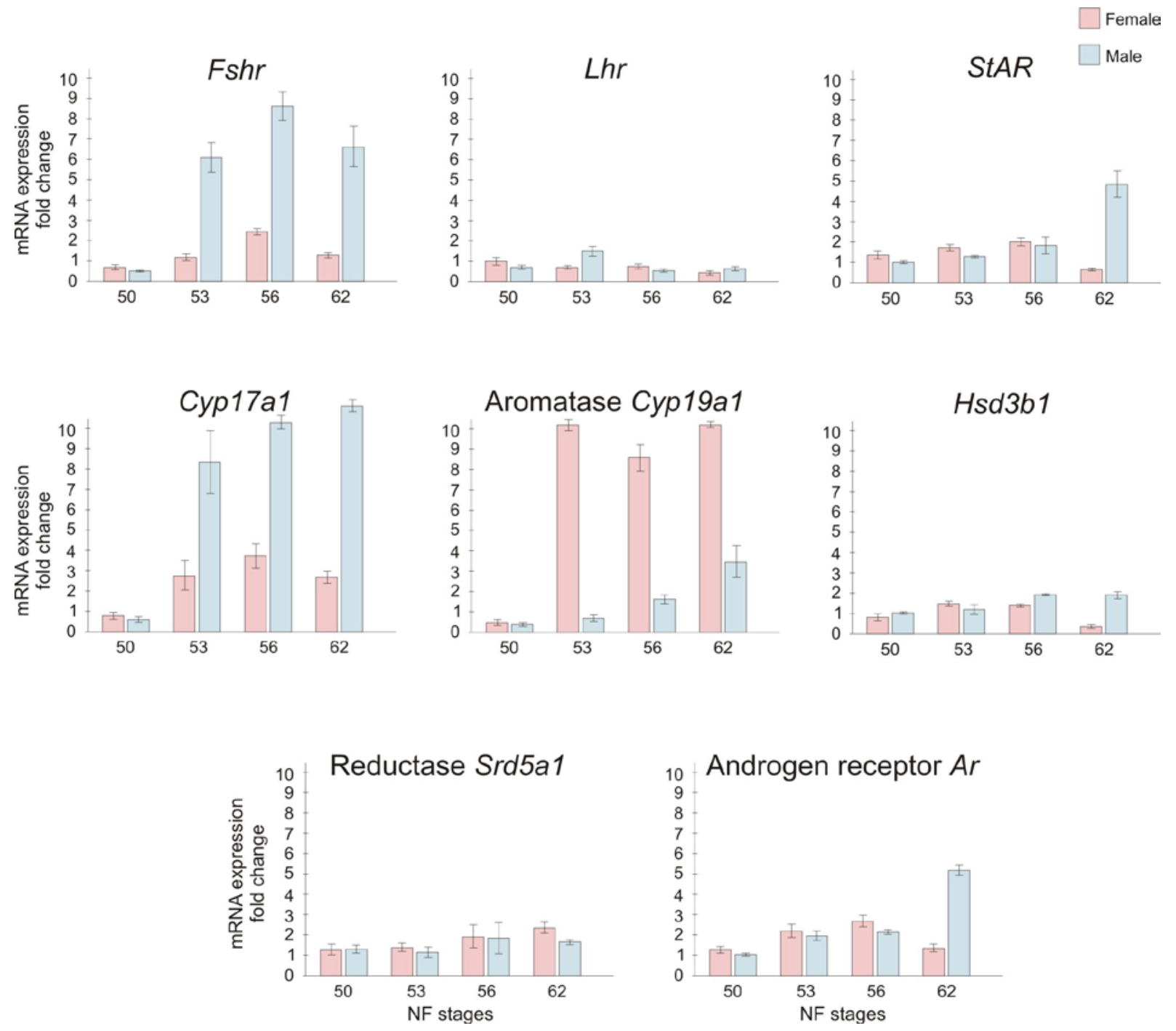
Fig. 13.

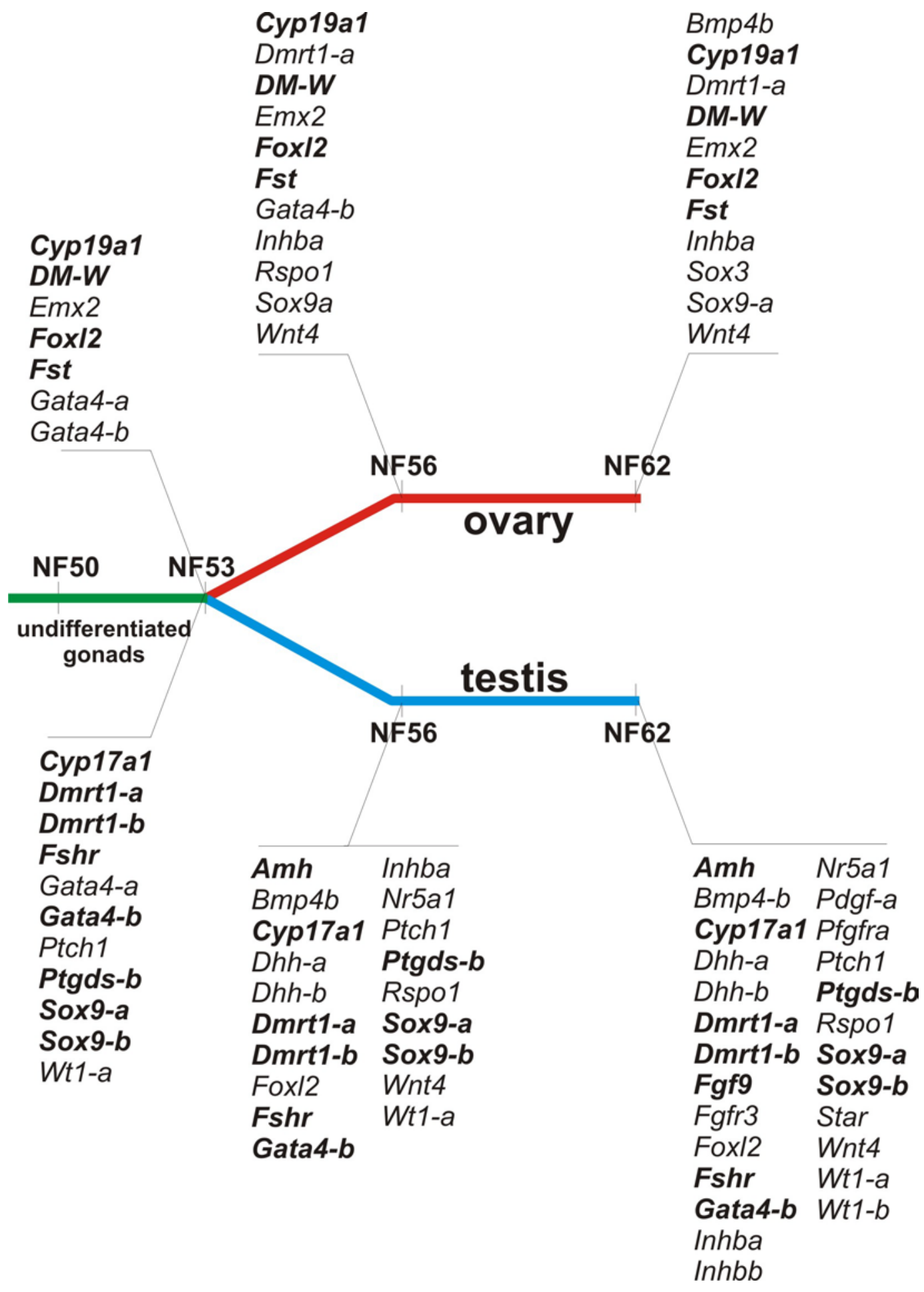

